\title{
The Importance of Intestinal Length in Triglyceride Metabolism and in Predicting the Outcomes of Comorbidities in Laparoscopic Roux-en-Y Gastric Bypass—a Narrative Review
}

\author{
Pirjo Käkelä ${ }^{1}$ (D) Tuomo Rantanen ${ }^{1} \cdot$ Kirsi A. Virtanen ${ }^{2,3}$ \\ Received: 25 January 2021 / Revised: 1 April 2021 / Accepted: 7 April 2021 / Published online: 29 April 2021 \\ (C) The Author(s) 2021
}

\begin{abstract}
In this narrative review, we will appraise if modification of the length of bypassed small intestine based on measured total small intestinal length could optimize the outcomes of the laparoscopic Roux-en-Y gastric bypass (LRYGB). We provide a summary of carefully selected studies to serve as examples and to draw tentative conclusions of the effects of LRYGB on remission of comorbidities. As the heterogeneity of the included studies varied in terms of outcomes, type of study, length of the bypassed small intestine, and the follow-up, a common endpoint could not be defined for this narrative article. To achieve efficient metabolic outcomes, it is important to carefully choose the small intestine length excluded from the food passage suited best to each individual patient.
\end{abstract}

Keywords Obesity $\cdot$ Gastric bypass $\cdot$ Comorbidity $\cdot$ Triglycerides $\cdot$ Weight Loss $\cdot$ Intestine

\section{Introduction}

Globally, obesity is affecting more than 600 million people and the trend is upward. More than half a million obese people are admitted to obesity surgery each year [1]. As a result,

\section{Key Points}

1. Small intestinal length has an impact on resolution of comorbidities and lipid metabolism in laparoscopic Roux-en-Y gastric bypass (LRYGB).

2. Small intestinal length associates with non-alcoholic fatty liver disease (NAFLD)

3. Predicting the outcomes of comorbidities is complex and depends on several individual factors, such as comorbidities and preoperative weight.

Pirjo Käkelä pirjo.kakela@kuh.fi

Tuomo Rantanen tuomora@gmail.com

Kirsi A. Virtanen

kirsi.virtanen@uef.fi

1 Department of Surgery, University of Eastern Finland and Kuopio University Hospital, Kuopio, Finland

2 Department of Public Health and Clinical Nutrition, University of Eastern Finland, Kuopio, Finland

3 Department of Endocrinology and Clinical Nutrition, Kuopio University Hospital, Kuopio, Finland significant numbers of people are living with a new anatomical condition. In 2019, the IFSO Global Registry amalgamated data from 61 different countries. About $58 \%$ of operations were laparoscopic sleeve gastrectomies [1].

Recommendations for bariatric surgery are changing worldwide. In 1991, the National Institutes of Health (NIH) Consensus Development Panel gave a significant number of recommendations for bariatric surgery [2]. These recommendations are a majority consensus, rather than evidence based and they are accepted with very minor variations in most western countries. Same recommendations are used in Finland and worldwide. Indications for bariatric surgery are a body mass index (BMI) of $\geq 35 \mathrm{~kg} / \mathrm{m}^{2}$ with at least one comorbid condition or a BMI of $\geq 40 \mathrm{~kg} / \mathrm{m}^{2}$. Age limits are set in Finland between 18 and 65 years, but an individual evaluation is possible [3].

In 2011, the International Diabetes Federation recommended bariatric surgery to patients with a BMI between 30 and 35 $\mathrm{kg} / \mathrm{m}^{2}$ who, regardless of weight loss and conventional medical therapy, have uncontrolled diabetes [4]. The National Institute for Health and Care Excellence and the American Diabetes Association followed similar recommendations [5]. Also, in Finland, the Current Care Guidelines was recently recommended in the same way [3]. These new guidelines increase significantly the need for bariatric surgery. Weight loss is recommended for all obesity-related diseases, but 
weight loss programs with conventional therapy are successful only for a fraction of obese people, and the long-term results are very modest [6]. Sleeve gastrectomy is the most frequently performed procedure. However, LRYGB is highly effective hormonal procedure for weight loss and for resolution of comorbidities [7]. In recent years, the role of different procedures has been revised following the postoperative outcomes from a metabolic and functional point of view. The superiority of bariatric surgery is recognized worldwide as a cost-effective treatment both in terms of weight loss, maintenance of weight loss, and remission of comorbidities, such as type 2 diabetes (T2DM), hypertension, hyperlipidemia, and non-alcoholic fatty liver disease (NAFLD) $[8,9]$. Sixty years after the introduction of the laparoscopic Roux-en-Y gastric bypass (LRYGB) by Mason and Ito [10], there is no consensus on the ideal length of the gastric bypass limbs. Much variability exists among surgeons even for similar patient BMIs. In literature, the reported length of the alimentary limb (AL) and biliopancreatic limb (BPL) ranges widely among surgeons (average 110 (range 35-250) $\mathrm{cm}$ and 48 (range 10-250) cm, respectively) [11] (Fig. 1). Some authors believe that the limb length currently used makes the LRYGB a mainly restrictive rather than malabsorptive procedure.

\section{Methods}

We systematically searched the MEDLINE literature, limited to English language articles. Using the same strategy, we

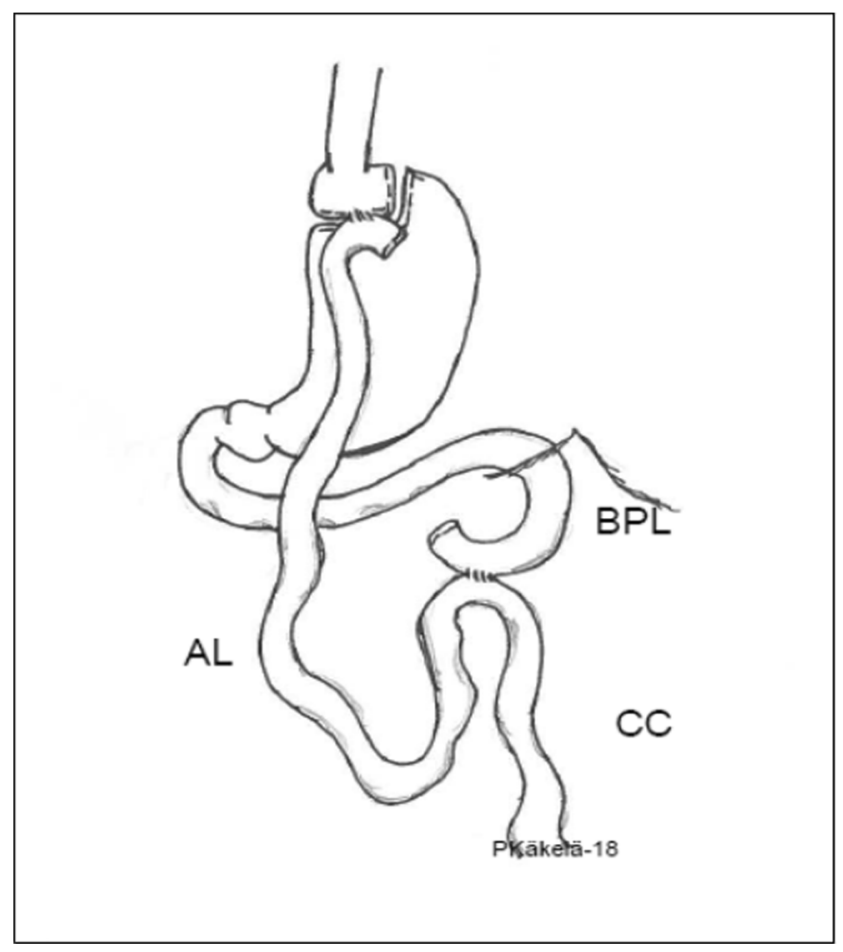

Fig. 1 Roux-en-Y gastric bypass searched the Cochrane database of evidence-based reviews and the Database of Abstracts of Reviews of Effects for articles reporting the effect of gastric bypass length on outcomes.

\section{Results}

LRYGB is the most frequently executed restrictive, malabsorptive [7], and hormonal [12] operation in Europe and in Latin America [1]. LRYGB is a gastric bypass featuring a gastric pouch, a gastro-jejunostomy and a jejunojejunostomy (Fig. 1). As a result of this configuration, absorption of nutrients occurs mostly distal to the jejunojejunostomy, when food particles interact with the digestive pancreatic enzymes. Thus, the length of functionally absorptive small intestine is decreased by $160-225 \mathrm{~cm}$ as a result of the operation. The degree of malabsorption can be modified by altering the length of these limbs. As a result, food is diverted from the small gastric pouch directly into the jejunum and bypassing the gastric remnant, duodenum, and proximal jejunum. However, according to DUCATI trial, some absorption of amino acids and glucose may also take place in the AL as well, through the saliva and succus which may digest proteins and carbohydrates [13].

When altering the gastrointestinal anatomy and physiology, the amount of food intake is reduced and nutrients are delivered more rapidly to the distal small intestine. Patients will lose weight, and they will also have favorable metabolic improvements due to the modifications in the enteroendocrine axis (e.g., increase of peptide YY (PYY), glucagon-like peptide-1 (GLP-1) levels) [14-16]. This all can lead to a loss of hunger and increase in satiety [17]. Exclusion of the proximal small intestine reduces the secretion of upper gastrointestinal factors such as anti-incretins, which are assumed to suppress insulin secretion or promote insulin resistance [12]. Changes in gut microbiota after the bypass may also influence weight by reduction of low-grade inflammation associated with obesity [18].

The length of the common channel (CC) is not routinely measured during LRYGB, and therefore, the length of the total small intestine remains unknown. In addition, the flexible elasticity of bowel makes its measurement sometimes rather subjective and variable and there is no recommended standard method for intestinal measurement. Currently, the data of the normal length of the total small intestine are mostly based on old cadaver studies [19-21]. Very few studies compare the ratio of the $\mathrm{AL}+\mathrm{BPL}$ to the length of the $\mathrm{CC}$ and their impact on resolution of comorbidities. A few publications have shown that after LRYGB, a short CC, which is $100 \mathrm{~cm}$ or less, leads to a resolution of more than $95 \%$ of comorbidities with $65 \%$ excess weight loss (\%EWL), and this has a better outcome than a long CC, more than $100 \mathrm{~cm} \mathrm{[22,} \mathrm{23].} \mathrm{When} \mathrm{the}$ length of the $\mathrm{CC}$ approaches $100 \mathrm{~cm}$, a significant impact on 
comorbidities and lipid metabolism is observed due to malabsorption [22]. According to the study of Käkelä et al., along with changes in lipid metabolism, a difference in liver steatosis between groups with different baseline small intestinal length has been found, suggesting that the small intestinal length also associates with NAFLD [24]. An inadequate bypass with a long $\mathrm{CC}$ may fail to reach its malabsorptive goal $[25,26]$, while a too short AL and CC may drive the patient to protein-calorie malnutrition in up to $20-25 \%$ of LRYGB procedures [27]. Individual total small intestinal length may be important in predicting the weight loss and resolution of metabolic comorbidities [22, 23]. Measuring the entire small intestine before LRYGB and tailoring the small intestinal limbs according to the BMI may prevent the risk of nutritional consequences in malabsorptive, revisional, and metabolic procedures [28]. During the first 12 weeks following obesity surgery, T2DM control may be achieved in $93 \%$ of patients with a short $\mathrm{CC}$ (1/3 of the total length of the small bowel) and in $58 \%$ of patients with a long CC (2/3 of the total length of the small bowel) [23]. In distal bypass with a short, $100 \mathrm{~cm} \mathrm{CC}$, resolution of T2DM reached 94\% at the 4-year follow-up [29].

Small intestinal length, gender, and age may be strong predictors of weight [28]. Older women have a shorter small intestine than older men [30]. A shorter small intestine could predispose to weight loss. Men have a longer small bowel and a larger body mass, and these could predispose to weight gain. Further, older people have difficulties to lose weight [28]. According to Nordgren et al., increased weight is positively associated with the small intestinal length [31]. In the contrary, we found that the small intestinal length was longer among women, despite of age [24], and that the weight loss was equal, despite the length of the $\mathrm{CC}$, as reported before [32]. However, there is conflicting data reporting that age does not correlate with the small intestinal length [28, 33] and patients with increased weight do not have longer small intestine [30].

A range of 100-200 $\mathrm{cm}$ for combined length of BPL or AL gives optimum results with LRYGB in most patients [26]. A long AL of more than one-third of the length of the total small intestine predicts both early and 5-year follow-up weight loss outcomes in superobese (BMI $\geq 50 \mathrm{~kg} / \mathrm{m}^{2}$ ) but not in morbidly obese $\left(B M I \leq 50 \mathrm{~kg} / \mathrm{m}^{2}\right)$ patients [25]. Choban et al. prefer an AL of approximately one-half of the length of the total small intestine [34]. For patients with a BMI $\leq 50 \mathrm{~kg} / \mathrm{m}^{2}, \operatorname{limb}$ lengths are not as crucial to successful weight loss [22]. A systematic review by Mahawar et al. [26], a study by Navez et al. [35], and the DUCATI trial of 444 patients [13] all agree that lengthening of the AL and shortening the $\mathrm{CC}$ do not seem to have an effect on the weight loss at short time follow-up. However, further reduction in the length of the $\mathrm{CC}$ may lead to an increased incidence of metabolic and nutritional complications [34]. Mahawar et al. found that malabsorption makes only a minor overall contribution of approximately $11.0 \%$ to weight loss after LRYGB [36]. The ratio of the BPL to the total length of the small intestine may be crucial. In patients with $\mathrm{BMI} \geq 60 \mathrm{~kg} / \mathrm{m}^{2}$, a ratio of $>45 \%$ was associated with higher $\%$ EWL at 2 and 3 years [37]. In patients with $\mathrm{BMI} \leq 60$ $\mathrm{kg} / \mathrm{m}^{2}$, the benefits of a longer BPL diminished during longterm follow-up [37]. The \%EWL was faster with the short CC but was similar in both groups at 48 months (70\% vs $74 \%$ ) [29].

Most of the obesity-related changes in lipid metabolism have been associated with NAFLD [38]. Most importantly, hypertriglyceridemia in obese individuals is closely associated with NAFLD [39]. In addition, cholesterol synthesis in the liver is increased in NAFLD [40, 41]. Accordingly, bariatric procedures produce significant improvements in NAFLD and levels of serum lipids, but the response varies widely due to anatomic alterations unique to each bariatric procedure [42]. Some studies suggest a better control of dyslipidemia with a short CC, because of increased lipid malabsorption [23]. It is not known if the different small intestinal length is associated with NAFLD and lipid metabolism and how much the response in serum lipids can be modified by different lengths of CC. Pinheiro et al. found out that dyslipidemia was improved in $70 \%$ of patients with a short CC (1/3 of the total length of the small bowel), whereas only $57 \%$ of the patients with a long CC (2/3 of the total length of the small bowel) showed improvement in dyslipidemia [23]. Nelson et al. found that dyslipidemia was resolved in $68 \%$ of patients with a short CC, whereas only $44 \%$ of the patients with a long CC showed improvement [43]. In contrast, Valera-Mora et al. suggested that changes in serum lipids in response to surgery are independent of the length of the CC [44]. According to the study of Käkelä et al., hyperlipidemia improved in about $70 \%$ of patients after surgery [24] which is in line with previous studies [23, 45]. Also, serum triglyceride (TG) levels associated with the small intestinal length before and the length of the CC after LRYGB [24], suggesting that the small intestinal length regulates lipid metabolism, as published before [44, 46, 47]. It is important to note that CC length after surgery was variable between the study groups, while the length of the AL and BPL was the same in every group [24]. Therefore, the differences between the study groups after the surgery are likely to be due to different lengths of the $\mathrm{CC}$. There are also several other studies that have found that the CC length associates with more than $95 \%$ resolution or improvement in obesity-related comorbidities including hyperlipidemia [22, 44, 46-48].

\section{Discussion}

Bariatric surgery is an effective long-term treatment for severe obesity that results in long-term weight loss; improvement and remission of obesity-related comorbidities, particularly 
T2DM, dyslipidemia, and NAFLD; improvement in quality of life; and prolonged survival. Individual total small intestinal length may be important in predicting the weight loss and resolution of metabolic comorbidities.

The fact that the length of the $\mathrm{AL}$ is of limited relevance to postoperative weight loss for the patients with $\mathrm{BMI} \leq 50 \mathrm{~kg} /$ $\mathrm{m}^{2}$ but may make a difference for the superobese (BMI $\geq 50$ $\mathrm{kg} / \mathrm{m}^{2}$ ) is not surprising. The evidence from the distal gastric bypass and biliopancreatic diversion literature is clear. The degree of malabsorption is dependent on the length of the $\mathrm{CC}$ and the ratio of the bypassed AL+BPL. If malabsorption and improvement in dyslipidemia is a primary goal of the gastric bypass, preoperative measurements should focus on the length of the $\mathrm{CC}$, rather than the $\mathrm{AL}$ and the BPL. However, current clinical evidence suggests that malabsorption is not as important as it was thought of in the past, with regard to both weight loss and improvement of lipid metabolism. On the contrary, these features are mediated primarily by gut-related hormonal processes [14-16]. Limitations of the available literature include variation in the length of the small intestinal limbs, which makes comparison of results between the studies challenging. Some studies consider the same AL or BPL short while the others long. Furthermore, the criteria used to determine the length of the limbs vary significantly among surgeons [48].

Together, these findings suggest that not only the small intestinal length regulates lipid absorption, but also gutrelated hormones after obesity surgery. However, modification of the length of bypassed small intestine based on measured total small intestinal length might optimize the outcomes of the elective LRYGB. Additionally, Käkelä et al. suggest that instead of constructing the standard bypass, the ratio of the bypassed $\mathrm{AL}+\mathrm{BPL}$ vs $\mathrm{CC}$ length should be $2 / 3$ vs $1 / 3$ of the total length of the small bowel when better control of dyslipidemia is aimed for [24]. The exact mechanism remains open but could be related to alterations in lipid absorption. This requires that the length of the total small intestine is measured preoperatively when constructing a gastric bypass, the procedure we have systematically been performing. However, we must pay attention to the possibility of inadvertent injury of the small intestine when measuring it.

\section{Conclusion}

The question, "how important the intestinal length is in triglyceride metabolism and in predicting the outcomes of comorbidities in LRYGB?", cannot be answered in definitive terms but must be answered for each patient individually, as it is complex and depends on several individual factors, such as comorbidities and preoperative weight.
Funding Open access funding provided by University of Eastern Finland (UEF) including Kuopio University Hospital.

\section{Declarations}

Ethical Approval For this type of study, formal consent is not required.

Informed Consent Informed consent does not apply in this study.

Conflict of Interest The authors declare no competing interests.

Open Access This article is licensed under a Creative Commons Attribution 4.0 International License, which permits use, sharing, adaptation, distribution and reproduction in any medium or format, as long as you give appropriate credit to the original author(s) and the source, provide a link to the Creative Commons licence, and indicate if changes were made. The images or other third party material in this article are included in the article's Creative Commons licence, unless indicated otherwise in a credit line to the material. If material is not included in the article's Creative Commons licence and your intended use is not permitted by statutory regulation or exceeds the permitted use, you will need to obtain permission directly from the copyright holder. To view a copy of this licence, visit http://creativecommons.org/licenses/by/4.0/.

\section{References}

1. Ramos A, Kow L, Brown W, et al. The International Federation for the Surgery of Obesity and Metabolic Disorders. In: Fifth IFSO Global Registry Report; 2019.

2. NIH conference. Gastrointestinal surgery for severe obesity. Consensus Development Conference Panel. Ann Intern Med. 1991;115(12):956-61.

3. Current care guidelines: obesity, adults. Käypä hoito-suositus: Lihavuus, aikuiset. 2020. Duodecim.https://www.kaypahoito.fi/ hoi50124

4. Dixon JB, Zimmet P, Alberti KG, et al. International Diabetes Federation Taskforce on Epidemiology and Prevention. Bariatric surgery: an IDF statement for obese type 2 diabetes. Diabet Med. 2011;28(6):628-42.

5. National Institute for Health and Clinical Excellence. Obesity: identification, assessment and management of overweight and obesity in children, young people and adults. 2014:CG189. Available online at: http://www.nice.org.uk/guidance/cg189

6. Ribaric G, Buchwald JN, McGlennon TW. Diabetes and weight in comparative studies of bariatric surgery vs conventional medical therapy: a systematic review and meta-analysis. Obes Surg 2014. 24(3):437-55.

7. Miller K, Pump A, Hell E. Vertical banded gastroplasty versus adjustable gastric banding: prospective long-term follow-up study. Surg Obes Relat Dis. 2007;3(1):84-90.

8. Deitel M, Dixon J. Comorbidities of morbid obesity and determination of optimal weight. In: Deitel M, Dixon J, Gagner M, Madan A, Himpens J, editors. Handbook of obesity surgery 2010 . 1st ed. Toronto: FD-Communications. ISBN 978-0-9684426-5-4.

9. Hatoum IJ, Kaplan LM. Advantages of percent weight loss as a method of reporting weight loss after Roux-en-Y gastric bypass. Obesity (Silver Spring). 2013;21(8):1519-25.

10. Mason EE, Ito C. Gastric bypass. Ann Surg. 1969;170:329-39.

11. Madan AK, Harper JL, Tichansky DS. Techniques of laparoscopic gastric bypass: on-line survey of American Society for Bariatric 
Surgery practicing surgeons. Surg Obes Relat Dis. 2008;4:166-72. discussion 172-3

12. Rubino F, R'Bibo SL, del Genio F, et al. Metabolic surgery: the role of the gastrointestinal tract in diabetes mellitus. Nat Rev Endocrinol. 2010;6(2):102-9.

13. Gadiot RPM, Leeman M, Biter LU, et al. Does the length of the common channel as part of the total alimentary tract matter? One year results from the multicenter Dutch Common Channel Trial (DUCATI) comparing standard versus distal Roux-en-Y gastric bypass with similar biliopancreatic bowel limb lengths. Obes Surg. 2020 December 01;30(12):4732-40.

14. Yousseif A, Emmanuel J, Karra E, et al. Differential effects of laparoscopic sleeve gastrectomy and laparoscopic gastric bypass on appetite, circulating acyl-ghrelin, peptide YY3-36 and active GLP-1 levels in nondiabetic humans. Obes Surg. 2014;24(2): 241-52.

15. Mans E, Serra-Prat M, Palomera E, et al. Sleeve gastrectomy effects on hunger, satiation, and gastrointestinal hormone and motility responses after a liquid meal test. Am J Clin Nutr. 2015;102(3):540 7.

16. Korner J, Bessler M, Cirilo LJ, et al. Effects of Roux-en-Y gastric bypass surgery on fasting and postprandial concentrations of plasma ghrelin, peptide YY, and insulin. J Clin Endocrinol Metab. 2005;90(1):359-65.

17. le Roux CW, Welbourn R, Werling M, et al. Gut hormones as mediators of appetite and weight loss after Roux-en-Y gastric bypass. Ann Surg. 2007;246(5):780-5.

18. Abdeen G, le Roux CW. Mechanism underlying the weight loss and complications of Roux-en-Y gastric bypass. Review. Obes Surg. 2016;26(2):410-21.

19. Chewal JP. Anatomy of jejunum and ileum. In: Chewal JP, editor. Surgery of esophagus, stomach and small intestine. Phildelphia: Little Brown; 1995. p. 784-8.

20. Evers B. Small intestine. In: Evers B, editor. Schwartz principles of surgery. Philadelphia.: McGraw Hill; 1999. p. 1217-57.

21. Guzman IJ, Fitch LL, Varco RL, et al. Small bowel length in hyperlipidemia and massive obesity. Am J Clin Nutr. 1997;30(7): 1006-8.

22. Stefanidis D, Kuwada TS, Gersin KS. The importance of the length of the limbs for gastric bypass patients-an evidence-based review. Obes Surg. 2011;21(1):119-24.

23. Pinheiro JS, Schiavon CA, Pereira PB, et al. Long-long limb Rouxen-Y gastric bypass is more efficacious in treatment of type 2 diabetes and lipid disorders in super-obese patients. Surg Obes Relat Dis. 2008;4(4):521-5.

24. Käkelä P, Männistö V, Vaittinen M, et al. Small intestinal length associates with serum triglycerides before and after LRYGB. Obes Surg. 2018;13:1-7.

25. Gleysteen JJ. Five-year outcome with gastric bypass: Roux limb length makes a difference. Surg Obes Relat Dis. 2009;5(2):242-7.

26. Mahawar KK, Kumar P, Parmar C, et al. Small bowel limb lengths and Roux-en-Y gastric bypass: a systematic review. Obes Surg. 2016;26(3):660-71.

27. Kalfarentzos F, Skroubis G, Karamanakos S, et al. Biliopancreatic diversion with Roux-en-Y gastric bypass and long limbs: advances in surgical treatment for super-obesity. Obes Surg. 2011;21(12): 1849-58.

28. Tacchino RM. Bowel length: measurement, predictors, and impact on bariatric and metabolic surgery. Surg Obes Relat Dis. 2015;11(2):328-34
29. Nelson WK, Fatima J, Houghton SG, et al. The malabsorptive very, very long limb Roux-en-Y gastric bypass for super obesity: results in 257 patients. Surgery. 2006;140(4):517-22.

30. Teitelbaum EN, Vaziri K, Zettervall S, et al. Intraoperative small bowel length measurements and analysis of demographic predictors of increased length. Clin Anat 2013. 26(7):827-32.

31. Nordgren S, McPheeters G, Svaninger G, et al. Small bowel length in inflammatory bowel disease. Int J Colorectal Dis. 1997;12(4): $230-4$.

32. Hosseinpour M, Behdad A. Evaluation of small bowel measurement in alive patients. Surg Radiol Anat 2008. 2008;30(8):653-5.

33. Lohsiriwat V, Wiangphoem N, Lohsiriwat $\mathrm{S}$. The length of small bowel in Thai patients. J Med Assoc Thai. 2014;97(5):525-9.

34. Choban PS, Flancbaum L. The effect of Roux limb lengths on outcome after Roux-en-Y gastric bypass: a prospective, randomized clinical trial. Obes Surg. 2002;12(4):540-5.

35. Navez B, Thomopoulos T, Stefanescu I, et al. Common limb length does not influence weight loss after standard laparoscopic Roux-enY gastric bypass. Obes Surg. 2016;26:1705-9.

36. Mahawar KK, Sharples AJ. Contribution of malabsorption to weight loss after Roux-en-Y gastric bypass: a systematic review. Obes Surg. 2017;27:2194-206.

37. Hamoui N, Anthone GJ, Kaufman HS, et al. Maintenance of weight loss in patients with body mass index $>60 \mathrm{~kg} / \mathrm{m}^{2}$ : importance of length of small bowel bypassed. Surg Obes Relat Dis. 2008;4:404 6.

38. Puri $\mathrm{P}$, Wiest $\mathrm{MM}$, Cheung $\mathrm{O}$, et al. The plasma lipidomic signature of nonalcoholic steatohepatitis. Hepatology. 2009;50(6):1827-38.

39. Vanni E, Bugianesi E, Kotronen A, et al. From the metabolic syndrome to NAFLD or vice versa? Dig Liver Dis. 2010;42(5):320 30.

40. Puri P, Baillie RA, Wiest MM, et al. A lipidomic analysis of nonalcoholic fatty liver disease. Hepatology. 2007;46(4):1081-90.

41. Simonen P, Kotronen A, Hallikainen M, et al. Cholesterol synthesis is increased and absorption decreased in non-alcoholic fatty liver disease independent of obesity. J Hepatol. 2011;54(1):153-9.

42. Heffron SP, Parikh A, Volodarskiy A, et. al. Changes in lipid profile of obese patients following contemporary bariatric surgery: a meta-analysis. Am J Med. 2016;129(9):952-959.

43. Nelson DW, Blair KS, Martin MJ. Analysis of obesity-related outcomes and bariatric failure rates with the duodenal switch vs gastric bypass for morbid obesity. Arch Surg. 2012;147(9):847-54.

44. Valera-Mora ME, Simeoni B, Gagliardi L, et al. Predictors of weight loss and reversal of comorbidities in malabsorptive bariatric surgery. Am J Clin Nutr. 2005;81(6):1292-7.

45. Jammah AA. Endocrine and metabolic complications after bariatric surgery. Saudi J Gastroenterol 2015. 2015;21(5):269-77.

46. Buchwald $\mathrm{H}$, Avidor $\mathrm{Y}$, Braunwald $\mathrm{E}$, et al. Bariatric surgery: a systematic review and meta-analysis. JAMA. 2004;292(14):1724 37.

47. Søvik TT, Aasheim ET, Taha O, et al. Weight loss, cardiovascular risk factors, and quality of life after gastric bypass and duodenal switch: a randomized trial. Ann Intern Med. 2011;155(5):281-91.

48. Savassi-Rocha AL, Diniz MT, Savassi-Rocha PR, et al. Influence of jejunoileal and common limb length on weight loss following Roux-en-Y gastric bypass. Obes Surg. 2008;18(11):1364-8.

Publisher's Note Springer Nature remains neutral with regard to jurisdictional claims in published maps and institutional affiliations. 